\title{
Is There Enough Effort by Corporations in Malaysia to Promote Ethical Leadership and Long-Term Growth? A Perspective Analysis
}

\author{
Anantha Raj A. Arokiasamy1, Alice Tamah² \\ ${ }^{1}$ RMIT International University, Vietnam \\ 2 Xiamen University, Malaysia
}

\begin{abstract}
Employees are under greater pressure to tackle more difficult ethical issues as global competition and economic demands rise. It focuses on the concept of ethical leadership, the personality traits of ethical leaders, and the views linked to the antecedents and results of ethical leadership. Following an ethical approach leads in a positive experience for everyone involved in a firm; the issue of ethical leadership is discussed in this article. Ethical leadership is a form of leadership in which individuals act in ways that are acceptable and essential for the greater good in all parts of their lives. Any individual in a management position should exercise ethical leadership. This is the most major ethical problem that our society and workplace confront, as well as the most significant ethical leadership task. This study provides possibilities for academics to investigate new findings in leadership style and aids in understanding how companies may produce ethical leaders in the workplace. A successful and efficient leader blends ethics and leadership, making their presence known and emerging as a role model to play a more positive and important role in a company. The presentation also addresses the subject of developing ethical leaders for the twenty-first century. One of the goals of university education is to develop students' common sense so that they may become effective citizens who can contribute constructively to our community and industry. This guarantees that teachers in charge of ethics curriculum and preparation in companies must ensure that future leaders grasp the ideas and implement ethical standards in their everyday job routines.
\end{abstract}

Keywords: Leaders, ethics, education, organization, teaching, and learning.

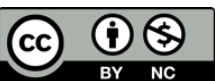

This is an open access article under the CC-BY-NC license

\section{INTRODUCTION}

Globalization has never been more linked and intertwined, making it one of the most powerful and pervasive influences in companies, cultures, and people's lives. Globalization appears to be unavoidable, and it threatens to overcome long-standing local, geographical, national, legal, and, perhaps, cultural barriers to material, intellectual, and social transformation (Webb, Vulliamy, Sarja, \& Hämäläinen, 2006). Globalization, liberalization, market shifts, and technology developments have all compelled businesses to reconsider their structures, systems, and processes, and they have definitely affected organizational ethics and leadership. Change is viewed as essential not just for an organization's existence, but also for its ethics, competitive edge, and progress (Christian, Moritz, \& Andreas Georg, 2012). 
The efficiency of a business, its performance, and the success of an organization are all strongly related to the quality, efficacy, and ethical attitude and approach of the firm's leader. On the contrary, the business world has seen a number of organizational scandals in the past, mostly as a result of the reckless and immoral behavior, attitude, and approach of the executives at the helm of affairs, so-called leaders of an organization. The cases of Enron and Satyam Computers in India are well-known examples of corporate frauds that cast serious doubt on the role and performance of executives in businesses (Ponnu \& Tennakoon, 2009).

\section{METHODS}

The present research is in descriptive research category and is of case study models. In case study, unlike testing research, the researcher manipulates independent variable and observes its effects on dependent variable. In addition, this research does not act like any other researcher, who studies a sample or large volume of samples and dependent variables in large volume and analysis them with society index.

\section{ETHICAL LEADERSHIP - A PERSPECTIVE}

In today's global economy, when individuals aspire to win via achievement and riches, there are ethical breaches everywhere. With large corporations suffering, the value of honesty in business and politics is becoming more evident. The importance of ethics is resurfacing (Kumar Mishra, 2020). Moral leadership has always existed, but it has recently gained prominence as a result of corporate ethical scandals. Moral leadership arises from a focus on the significance of ethics in key choices. Moral leadership is logical decision-making based on moral principles, whereas ethics is a collection of standards of proper behavior (Christian, 2011; Josep \& Josep, 2010). As demonstrated below, ethical lapses and dilemmas can occur for a number of reasons:

a) "Data is being misinterpreted for personal gain"

b) "Disrespect towards coworkers because of cultural differences"

c) "Unprofessional behavior that violates the code of conduct"

Even though each company's workplace ethics are extremely subjective, good ethics in business lead to greater productivity and positive employee morale (Rasche, 2020). Understanding the study of moral conduct is critical for understanding the practical challenges of an effective, moral leader. Ambivalence, sense of self, and ambivalence are three functional impediments that create the ethical problem experienced at work, according to the research. Moral leaders must strike a balance between all three characteristics, especially when challenged with ethical quandaries. Moral leadership demands steadfast determination, the rejection of hasty decisions, and devotion. Understanding and skillfully managing these obstacles are essential elements of moral leadership (Price, 2018).

Ethical leadership is a notion that is still in its infancy. Ethics debates, on the other hand, are prevalent in "almost any type of organization." Several unlawful acts and disputes are taking place in various organizations. In recent years, one has witnessed the fall of Enron, which was caused in part by dishonest behavior. According to Ciulla, Knights, Mabey, and Tomkins (2018a), Enron's lack of professional leadership damaged thousands of workers, spurred more government monitoring, and undermined public faith in the financial industry. Ethical leadership is a notion that 
is still in its infancy. Ethics debates, on the other hand, are prevalent in "almost any type of organization." Many unlawful acts and disputes are taking place in many organizations. In recent years, one has witnessed the fall of Enron, which was caused in part by dishonest behavior. According to Ciulla et al. (2018a), Enron's lack of professional leadership damaged thousands of employees, spurred more government monitoring, and undermined public faith in the financial industry. This implies that unethical activity by one person might set off a chain reaction of unethical behavior in an organization. One of the most pressing challenges affecting businesses today, according to Kumar Mishra (2020), is a lack of ethical activity and ethical leadership. According to Josep \& Josep (2010), the new corporate environment is skeptical of ethics. Because of examples of unethical behavior, businesses have been pushed to reconsider their strategic approach, teaching them that responsible leadership is the way to prosperity.

If a firm wishes to enhance its legal or moral environment, it should start by examining its leader's ethical principles. Leadership and ethics are intimately intertwined. Ineffective leadership is the outcome of unethical actions. Mills, Sanders, and Hussain (2019) define ethics as having two components. First and foremost, it involves the ability to discern between what is good and what is wrong. Second, it involves a commitment to do what is just and right. Ethical behavior demands action. He defined ethics as a collection of principles that teach individuals how to behave in such situations based on moral duties and values derived from notions of right and wrong. Leaders must be perceived as desired, trustworthy, and legitimate by their subordinates in order for them to be ethical leaders and have an influence on ethical outcomes. This is done through engaging in exactly permissible behaviors motivated by charity, such as transparency and fairness. According to Bush, many ethical leadership arguments are congruent with transformational and charismatic leadership paradigms (2007). Mardiana Yusuf identified seven ethical leader practices: fairness, people-orientation, task clarity, ethical guidance, climate orientation, power-sharing, and honesty (2018). According to Bardy and Rubens (2010), the most important ethical leadership principles are as follows:

1. "Dignity and honesty" (including consistency of actions with espoused values)

2. "Behavior aimed at communicating or enforcing ethical principles"

3. "Conduct that demonstrates decency, sympathy, and respect for the needs and feelings of others rather than attempts to control, harass, and misuse others for personal benefit" (no favoritism or use of incentives to encourage inappropriate behavior) and

4. "Behavior that demonstrates kindness, compassion, and concern for the needs and feelings of others rather than attempts to influence, threaten, and exploit others for personal gain"

In the table below Bardy and Rubens (2010) the criteria for evaluation of ethical and unethical leadership are presented.

Table 1: Criteria for evaluation of ethical leadership

\begin{tabular}{|l|l|l|}
\hline Criterion & Ethical Leadership & Unethical Leadership \\
\hline $\begin{array}{l}\text { 1. Use of leader power and } \\
\text { influence }\end{array}$ & $\begin{array}{l}\bullet \text { To serve followers and the } \\
\text { organization }\end{array}$ & $\begin{array}{l}\text { To satisfy personal needs and } \\
\text { career objectives }\end{array}$ \\
\hline
\end{tabular}

13

ISSN 2807-9663 (Online) | 2807-9671 (Print) 


\begin{tabular}{|c|c|c|}
\hline $\begin{array}{l}\text { 2. Handling diverse } \\
\text { interests of the multiple } \\
\text { stakeholders }\end{array}$ & $\begin{array}{l}\text { - Attempts to balance and } \\
\text { integrate them }\end{array}$ & $\begin{array}{l}\text { Favors coalition partners of } \\
\text { who offer the most benefits }\end{array}$ \\
\hline $\begin{array}{l}\text { 3. Development of a vision } \\
\text { for the organization }\end{array}$ & $\begin{array}{l}\text { - Develops a vision based on } \\
\text { follower input about their } \\
\text { needs, values, and ideas }\end{array}$ & $\begin{array}{l}\text { - Attempts to sell a personal } \\
\text { vision as the only way for the } \\
\text { organization to succeed }\end{array}$ \\
\hline $\begin{array}{l}\text { 4. The integrity of leader } \\
\text { behavior }\end{array}$ & $\begin{array}{l}\text { - Acts in a way that is consistent } \\
\text { with espoused values }\end{array}$ & $\begin{array}{l}\text { - Does what is expedient to } \\
\text { attain personal objectives }\end{array}$ \\
\hline $\begin{array}{l}\text { 5. Risk-taking in leader } \\
\text { decisions and actions }\end{array}$ & $\begin{array}{l}\text { - Is willing to take personal } \\
\text { risks and actions to } \\
\text { accomplish a mission or } \\
\text { achieve the vision }\end{array}$ & $\begin{array}{l}\text { Avoids necessary decisions or } \\
\text { actions that involve personal } \\
\text { risk to the leader }\end{array}$ \\
\hline $\begin{array}{l}\text { 6. } \\
\text { Communication of } \\
\text { relevant information } \\
\text { operations }\end{array}$ & $\begin{array}{l}\text { Makes a complete and timely } \\
\text { disclosure of information } \\
\text { about events, problems, and } \\
\text { actions }\end{array}$ & $\begin{array}{l}\text { - Uses deception and distortion } \\
\text { to bias follower perceptions } \\
\text { about problems and progress }\end{array}$ \\
\hline $\begin{array}{l}\text { 7. Response to criticism } \\
\text { and dissent by followers }\end{array}$ & $\begin{array}{l}\text { - Encourage critical evaluation } \\
\text { to find better solutions }\end{array}$ & $\begin{array}{l}\text { - Discourages and suppresses } \\
\text { any criticism or dissent }\end{array}$ \\
\hline $\begin{array}{l}\text { 8. Development of follower } \\
\text { skills and self- } \\
\text { confidence }\end{array}$ & $\begin{array}{l}\text { Uses coaching, mentoring, and } \\
\text { training to develop followers }\end{array}$ & $\begin{array}{l}\text { De-emphasize development } \\
\text { to keep followers weak and } \\
\text { dependent on the leader }\end{array}$ \\
\hline
\end{tabular}

According to Darcy (2010), the working environment of businesses today is such that employees are skeptical about the application of real principles and ethical norms. According to a qualitative study, 66 percent of respondents doubt the presence of ethics in leadership conduct, suggesting that there is a "trust crisis" in leadership (Frank, 2002). According to the survey, one of the most critical difficulties for today's leaders is creating trust and building trustworthy connections at work. To verify the scale, the researchers conducted various concept validation experiments and concluded that supervisory ethical leadership is positively related to fairness, integrity, the idealized impact dimension of transformational leadership, and emotional confidence in the leader (Bass and Avolio, 2000). Brown et al. (2005) defined ethical leadership as "an manifestation of normatively appropriate behavior via personal acts and interpersonal connections, and encouragement of such conduct to followers through two-way communication, viz., reinforcement and sound decision-making." Brown et al. (2005) define ethical leadership as leaders' normatively approved behavior that is comparable and consistent among subordinates: Ethical leadership is guided by a regard for ethical ideas and ideals, as well as the dignity and rights of others. As a result, it is associated with concepts such as trust, honesty, thoughtfulness, charm, and justice (Brown et al., 2005).

\section{ETHICAL LEADER}

A person who leads ethically is someone who adheres to essential moral ideals. To be an ethical leader, one must adhere to a more fundamental moral code. Based on a thorough review of the literature, the following definition was developed: "ethical leadership is defined as the demonstration of normatively appropriate behavior through personal actions and interpersonal 
relationships, as well as the promotion of such behavior to followers through two-way communication" (Ciulla, Knights, Mabey, \& Tomkins, 2018b). When it comes to ethical leadership, the emphasis is on always acting in a reasonable and acceptable manner. It is comprised of the following main elements:

a) Role model - "An ethical leader exhibits traits that serve as an example for others." Those surrounding an ethical leader notice and recognize his behaviors. By operating in an ethical, genuine, and unselfish manner, the ethical leader earns the loyalty of his colleagues. As a consequence, they will view him favorably and follow his decisions."

b) Teacher - "An ethical leader must teach peers about ethics, particularly when they are confronted with an ethical dilemma at work."

c) Effective communication - "Ethical leaders who are successful are generally strong communicators. It is the obligation of the ethical leader to continually work with other team members and to avoid drawing comparisons based on personal interests. Each conversation may take place in a friendly environment that benefits the team and instills confidence."

From individual staff on the organizational level to departmental level and top-level, ethical leaders' decisions influence their environment and the whole organization:

i. Individual employee: "As an ethical boss, it is important to maintain a healthy work climate. He serves as a role model and is in a good position to connect and inspire them".

ii. The team: "An ethical leader empowers a team and is willing to communicate and collaborate with the whole team on a variety of topics. When people get along with each other, team morale is generally higher. When his team members do not behave integrally or politely toward one another, the ethical chief has a huge impact on this and calls them out on it".

iii. Organization: "The importance of having a good outlook in the workplace has a lot to do with improving the organization's overall wellbeing. It will filter through across the company if people treat each other with dignity and appreciate each other's views. Ethical leadership guarantees that an organization is a secure and trusted environment where individuals can develop individually, form friendships, and contribute to the organization's overall goals".

Basic rules of conduct those ethical leaders should follow to be considered true leaders are outlined as follows:

a) Leader principle: "a leader is foremost a member of the company and its spokesman, therefore his deeds must serve the purpose and benefits of the corporation".

b) Constituents' principle: "leaders respect their co-workers and perceive them as people who store common purpose. Their individuality and freedom are accepted within the borders of ethical behavior". 
c) Outcome principle: "a leader connects values to stakeholder support as well as societal legitimacy. Company mission, vision, values, and goals (strategy \& tactics) are outlined within an understanding of ethical ideals".

d) Process/skills principle: "the leader is open to different opinions and ideas, views and creates an atmosphere of dynamic and fruitful communication".

e) Situation/context principle: "moral judgments are used to make ethical decisions and when crossing the boundaries of different ideas. The ethical leader knows the limits of the values and ethical principles they live".

f) Ethics principle: "a leader understands leadership and ethics as an integrated process and frames actions and purpose in ethical terms".

One of the Center for Ethical Leadership's founders, Price (2018), developed the 4-V model to convey ethical leadership (Figure 1). This paradigm seeks to combine internal attitudes and ideals with real attitudes and actions for the greater benefit. The letters symbolize values, vision, voice, and virtue. These traits help to shape the growth of a good ethical leader. The ethical leader must grasp and apply these fundamental concepts in all aspects of his or her life. The paradigm creates a framework for aligning internal variables (beliefs and values) with exterior beliefs (behavior and actions) in order to attain a common goal.

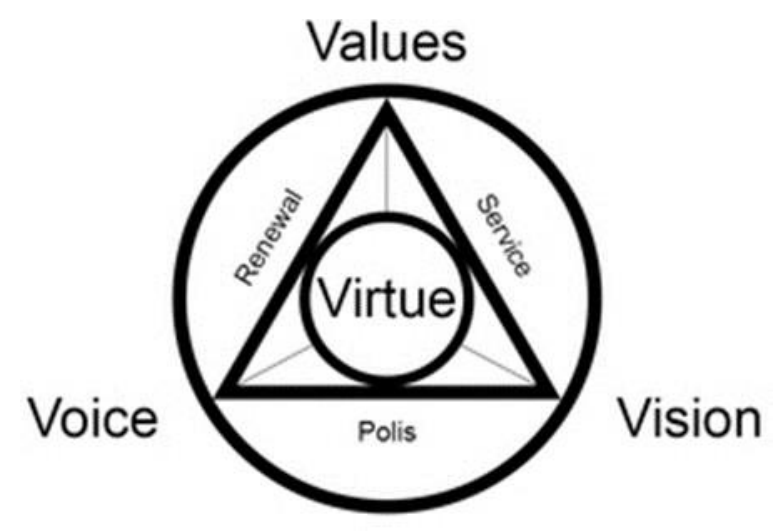

Figure 1: 4-V Model of Ethical Leadership Development

Leaders, according to this paradigm, make the difference. The first stage is to gain selfawareness and identify one's basic principles. Only then can the ethical leader express his fundamental beliefs with others while also connecting himself to society.

- Value - "to develop good ethical leadership, the leader needs to first go in search of his core values".

- Vision - "here it is about the leader's ability to implement his actions in such a way that they lead to a certain good vision".

- Voice - "the ethical leader must have a voice, to formulate the vision for others and to make it clear in a way that motivates them to act". 
- Virtue - "ethical leaders are role models because of their virtuous behavior and will strive to do the right things and act appropriately".

Other theories describe the reasons of ethical leadership in other ways than the 4-V ethical leadership paradigm. Building society, displaying integrity, demonstrating justice, serving others, and respecting others are the five major components of ethical leadership in a company, according to Plinio (2009). While integrating ethics to leadership and management styles, consider ethics when making decisions and creating limits within an organization, as well as when presenting thoughts. Developing an understanding of how to better design an ethical leadership system, sustain specific models, and make difficult judgments when opportunities arise.

\section{EDUCATION OF LEADER}

According to recent studies, leadership efficiency is a primary driver of an organization's performance, which reflects businesses' significant investments in leadership-focused initiatives. Leadership abilities are in high demand, and a graduate degree will assist students in achieving this goal. Formal ethical education in engineering programs focuses mainly on establishing human ethical principles and exploring solutions to particular ethical dilemmas, according to a review of research, textbooks, and curricula on ethical education (along with my observations over the years). However, modern curriculum and ethics instruction does not go far enough in preparing ethical leaders by educating students and scholars that ethical leadership is almost entirely about their actions and that the fundamental idea is to behave ethically and the organization can take care of the rest. We need to draw on existing methods to educate engineers that true ethical leadership necessitates rigorous, constructive, and organizational steps in the creation of ethical organizations. The foundation of ethical leadership is ethical action as a guide, but we also need to educate students and practitioners on how to put organizational structures and processes to help:

a) "Ethical behavior is understood and praised on a systematic level".

b) "Illegal and immoral behavior is quickly detected and handled".

c) "Ethical reasoning and problem-solving skills are regularly established and exercised".

Brown et al. offered one of the most comprehensive definitions of the word (2005). They described ethical leadership as "the presentation of normatively right behavior through personal acts and interpersonal connections, as well as the encouragement of such behavior to followers through two-way communication, reinforcement, and decision-making" (Brown et al., 2005, p. 120). According to this concept, ethical leaders act as role models of ethical conduct, attempting to instill such behavior in their followers through the use of communication and reinforcement systems to convey ethical norms and reward (discipline) ethical (unethical) behavior, respectively. Furthermore, while not specifically stated in the definition, Brown et al. (2005)'s conception implicitly includes preventing damage to employees as well as acting in their best interests (Stouten et al., 2012).

To establish ethical organizations, leaders must use an intentional and constructive framework approach. To produce real ethical leaders, we must teach students and professionals how to analyze and shape ethical organizations using a thinking approach. The fundamental objective of engineer ethics education should be to achieve this. It highlights the significance of 
global ethical leadership in achieving this goal. Individual leaders' dedication to honesty and excellence as basic ideals is a major inner motivation of ethical leadership. Members, like individuals, do not develop a clear code of conduct overnight; it takes time and experience. Leadership, according to Anderson, Woods, and Walker (2019), must produce ethical representatives. To that aim, colleges must prioritize the development of an ethical program. On a worldwide scale, one strategy is to include broad management ethics education and to oppose moral relativism. To become a successful ethical leader, you must learn how to better construct an ethical management plan, promote these practices, and make difficult decisions when the chance arises. Education is a useful tool for defining one's moral compass (Christian, 2011).

\section{METHODOLOGY}

After discussing some of the major presuppositions of managerial ethical leadership, I'd like to discuss three fundamental normative-ethical tasks of leadership: - perceiving, interpreting, and creating reality; - being responsible for the effects of one's decisions on the people involved; and - being responsible for the implementation of corporate goals. These three activities are inextricably linked. The manner in which leadership decisions are made is determined by the leader's perspective and interpretation of reality; in turn, his or her decisions affect reality to a large extent. If the business is viewed as a productive social system, achieving productive goals will have a wide variety of implications for the individuals involved. Human dignity cannot be separated from the organizational, economic, and financial environment. As previously said, management ethical leadership entails making responsible decisions in a complicated scenario. As a result, if this complicated challenge of management ethical leadership is split into numerous relatively small partial problems, the work is not completed, but disregarded. As a result, I encourage the reader to regard the following divides as conceptual categories - beneficial for greater comprehension rather than actual distinctions.

\section{PERCEIVING, INTERPRETING, AND CREATING REALITY}

To take on responsibility, the leader must first observe and comprehend reality. Otherwise, it's blind men guiding blind men: "They are blind men leading blind men; and if one blind man leads another, both will fall into a pit." (Matthew 15:15-14) Understanding is a necessary condition for making sound decisions and acting appropriately. Many managerial errors arise not because the wrong strategy was adopted, but because the situation-analysis itself is deceptive. To prevent this blunder, one must maintain a constant awareness to reality. Unpleasant or unsettling information that might have serious implications should not be removed in advance - deliberately or unconsciously - by the information gatherers. Only by taking the risk of being honest will the leader be able to build a foundation for managerial ethical leadership.

\section{BEING RESPONSIBLE FOR THE EFFECT OF ONE'S DECISIONS ON THE HUMAN BEINGS CONCERNED}

I emphasized the imbalance that occurs in the connection between leaders and followers, an asymmetry that exists whether leadership is defined as personal influence over subordinates or as corporate direction. This imbalance is sharply opposed by the enlightenment's urge to advance toward the enfranchisement and maturity of all persons. If one could cleanly separate the subordinate as an employee from the subordinate as a human, the issue might be resolved pretty 
quickly. In the workplace, the employee may be a skilled and dependable worker, while at home, he or she might be a caring and responsible husband and parent. Our roles in many aspects of life - job, family, politics, etc. - are unique and yet inextricably linked because, despite the variety of roles, the subject of the roles stays the same. This indicates that a leader's actions affect employees as persons as well as technical, economic, and financial repercussions. At this point, a fundamental question arises: to what degree, if any, is the dignity of the persons involved honored, or are the individuals involved just utilized as a means, or are they also acknowledged as subjects?

\section{BEING RESPONSIBLE FOR THE IMPLEMENTATION OF CORPORATE GOALS}

If we were pleased with our observations thus far, leadership would be quite straightforward. What is at stake, however, is the corporation's leadership, i.e. the leadership of a goal-oriented productive social system. This aspect, too, is crucial in terms of ethics. Decisions must be made in a highly goal-oriented way not just at the highest level of leadership, but also at all lower levels. What does management ethical leadership imply in terms of goal-orientation? If one accepts the frequently invoked "autonomy" of the business world, which managers must adhere to, ethics is put outside the business world and can be utilized - in an emergency - as a correction from without. In this situation, ethics is regarded as the sole responsibility of educational, religious, and other organizations "outside" of the corporate sector.

\section{CONCLUSION}

Managerial ethical leadership is neither the panacea for all ills, nor is it the path to success, happiness, and salvation. Because the leader's decision and action space is constrained by a variety of circumstances imposed by the organization, the economy, and other variables, managerial ethical leadership must be rooted in corporate ethics and business ethics. Is it feasible for a company to be both lucrative and competitive while being ethical? Business development and ethical conduct are intimately connected, according to Saleh, Nakonechny, St. Denis, and Nichols (2017): ethics and competitiveness are inexorably linked. According to By and Burnes, members are at conflict with the current belief culture (2013). This system teaches that how we dress, drive, and live defines us, and that what we own symbolizes our value. She cautions that similar ideas have been replicated in the business sector, where CEOs of firms such as Enron and WorldCom have lately sought profits to the point of violating ethical conventions. Given the importance of leadership in shaping corporate culture and normative behavior, global leaders must have a strong spiritual and ethical compass (Sanders \& Grint, 2019). This is especially important when international corporations expand, since they now have a wider potential than ever before to influence employees, individual communities, and the environment. To create a just and prosperous society, we educators must focus on values and education in order to become ethical global leaders.

\section{REFERENCES}

AlSagheer, A., \& Al-Sagheer, A. (2011). Facultys Perceptions Of Teaching Ethics And Leadership In Engineering Education. Journal of international education research, 7(2), 55-66. Amiridis, K. (2018). The Shadow of Sophocles: Tragedy and the Ethics of Leadership. Business ethics quarterly, 28(1), 15-29. 
Anderson, M., Woods, A. D., \& Walker, R. (2019). THE LINKAGE OF ETHICS AND LEADERSHIP TO THE DECISION MAKING PROCESS OF HBCU COLLEGE PRESIDENTS. Academy of educational leadership journal, 23(1), 1-11.

Bardy, R., \& Rubens, A. (2010). Is there a transatlantic divide?: Reviewing Peter F. Drucker's thoughts on ethics and leadership of US and European managers. Management decision, 48(4), 528540 .

Bush, V. B. (2007). Higher Ground: Ethics and Leadership in the Modern University (review). Review of higher education, 30(4), 474-475.

By, R. T., \& Burnes, B. (2013). Organizational Change, Leadership and Ethics: Leading Organizations towards Sustainability. London: Routledge.

Brown, M. E., Treviño, L. K., and Harrison, D. A. (2005). Ethical leadership: a social learning perspective for construct development and testing. Org. Behav. Hum.

Decis. Process. 97, 117-134. doi: 10.1016/j.obhdp.2005.03.002

Christian, V. (2011). Development of a Scale Measuring Discursive Responsible Leadership. Journal of business ethics, 98(S1), 57-73.

Christian, V., Moritz, P., \& Andreas Georg, S. (2012). Responsible Leadership in Global Business: A New Approach to Leadership and Its Multi-Level Outcomes. Journal of business ethics, 105(1), 1-16.

Ciulla, J. B., Knights, D., Mabey, C., \& Tomkins, L. (2018a). Guest Editors' Introduction: Philosophical Approaches to Leadership Ethics II: Perspectives on the Self and Responsibility to Others. Business ethics quarterly, 28(3), 245-250.

Ciulla, J. B., Knights, D., Mabey, C., \& Tomkins, L. (2018b). Guest Editors' Introduction: Philosophical Contributions to Leadership Ethics. Business ethics quarterly, 28(1), 1-14.

Hermannsdottir, A., Štangej, O., \& Kristinsson, K. (2018). When being good is not enough: Towards contextual education of business leadership ethics. Management (Split, Croatia), 23(2), 113.

Josep, F. M., \& Josep, M. L. (2010). Responsible Leaders for Inclusive Globalization: Cases in Nicaragua and the Democratic Republic of the Congo. Journal of business ethics, 93(S1), 93-111.

Kumar Mishra, N. (2020). Social distancing as social engineering \& health management: Applied ethics perspective to global management \& strategic leadership. Research in Globalization, 2,100032 .

Mardiana Yusuf, R. (2018). The effect of employee ability, hospital's ethic and leadership on job satisfaction through employee commitment: A study on an Indonesian Type A government hospital. The Journal of management development, 37(1), 40-52.

Mills, A., Sanders, A. K., \& Hussain, S. S. (2019). Fitting It All In? A Census of Undergraduate Ethics and Leadership Courses in Accredited U.S. Journalism and Mass Communication Programs. Journalism \& mass communication educator, 74(3), 265-275.

Plinio, A. J. (2009). Ethics and leadership. International journal of disclosure and governance, 6(4), 277-283.

Price, T. L. (2018). A "critical leadership ethics" approach to the Ethical Leadership construct. Leadership (London, England), 14(6), 687-706.

10 
Ponnu, C.H. and Tennakoon, G. (2009), "The association between ethical leadership and employee outcomes- the Malaysian case", Electronic Journal of Business Ethics and Organization Studies, Vol. 14 No. 1, pp. 21-31.

Rasche, A. (2020). "Speaking on Behalf of...": Leadership Ethics and the Collective Nature of Moral Reflection. Journal of business ethics, 163(1), 13-22.

Saleh, Z., Nakonechny, V., St. Denis, M., \& Nichols, D. (2017). BLAST: A Promising Approach to Service, Ethics, and Leadership Development in Rural Canada. Journal of youth development (Online), 12(3), 50-62.

Sanders, P., \& Grint, K. (2019). The interplay of the Dirty Hands of British area bombing and the wicked problem of defeating Nazi Germany in the Second World War - A lesson in leadership ethics. Leadership (London, England), 15(3), 271-295.

Webb, R., Vulliamy, G., Sarja, A., \& Hämäläinen, S. (2006). Globalization and leadership and management: a comparative analysis of primary schools in England and Finland. Research papers in education, 21(4), 407-432. 